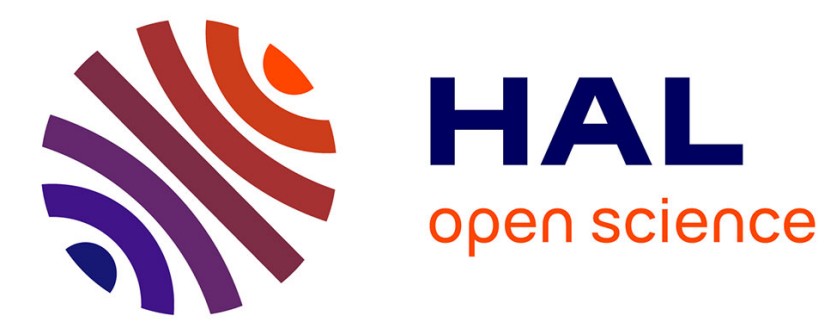

\title{
X-RAY EMISSION SPECTROSCOPY OF INDUSTRIAL CATALYSTS IN THE STEM
}

\author{
J. Lynch
}

\section{To cite this version:}

J. Lynch. X-RAY EMISSION SPECTROSCOPY OF INDUSTRIAL CATALYSTS IN THE STEM. Journal de Physique Colloques, 1984, 45 (C2), pp.C2-701-C2-704. 10.1051/jphyscol:19842162 . jpa00223835

\section{HAL Id: jpa-00223835 https://hal.science/jpa-00223835}

Submitted on 1 Jan 1984

HAL is a multi-disciplinary open access archive for the deposit and dissemination of scientific research documents, whether they are published or not. The documents may come from teaching and research institutions in France or abroad, or from public or private research centers.
L'archive ouverte pluridisciplinaire HAL, est destinée au dépôt et à la diffusion de documents scientifiques de niveau recherche, publiés ou non, émanant des établissements d'enseignement et de recherche français ou étrangers, des laboratoires publics ou privés. 
JOURNAL DE PHYSIQUE

Colloque C2, supplément au ${ }^{\circ} 2$, Tome 45 , février 1984

page $C 2-701$

\title{
$X$-RAY EMISSION SPECTROSCOPY OF INDUSTRIAL CATALYSTS IN THE STEM
}

\author{
J. Lynch \\ Institut Français du Pétrole, 1 et 4 avenue de Bois Préau, \\ 92502 Rueil-Malmaison, France
}

\begin{abstract}
Résumé - On présente des mesures réalisées sur des catalyseurs montrant certaines des limitations de $T$ 'analyse par émission $X$ dans le STEM. Ces limitations sont dues à la dégradation de l'échantillon et à la taille du faisceau. Le taux de comptage est comparé aux valeurs théoriques pour des tailles de sonde limitées par l'aberration sphérique. Une bonne corrélation est trouvée pour les particules de taille comprise entre 1 et $25 \mathrm{~nm}$.
\end{abstract}

Abstract - Examples of limitations to XES analysis of catalyst specimens in the STEM due to specimen degradation and probe size are presented. Absolute count rates as a function of particle size are compared with theoretical values for spherical aberration limited probes. Good agreement with the predicted size dependance is found in the range 1 to $25 \mathrm{~nm}$.

A major advantage of the STEM for the characterization of materials by X-ray emission spectroscopy is the ability to form a very small probe of high intensity. This has given rise to many applications in the chemical analysis of particles from a few nanometers to several microns in diameter $/ 1,2 /$. In this paper, examples are taken from the field of heterogeneous catalysts, consisting typically of light oxide carriers such as alimina or zeolites supporting heavy metal (Pt, Pd...) or alloy particles 1 to $50 \mathrm{~nm}$ in diameter. Typical applications to these systems are we11 documented $/ 3,4 /$. We will consider here two examples showing the effects of damage to the specimen and of the spatial distribution of electrons in the probe.

Some of the most beam sensitive materials in this field are in the zeolite family of supports. The example given in Figure 1 shows a crystal of an L-zeolite industrial preparation. This zeolite contains potassium. of interest here is the relative concentration of $A T, S i$ and $K$ as a function of distance from the centre. Figure 1 (a) shows the particle after analysis at five points, at the mid point of each edge and at the centre.

Severe structural damage is evident at the edges after 100 seconds. A potassium $X$-ray map (Fig. 1 (b)) shows that chemical changes have also been induced, the areas analysed are now potassium deficient. No evidence of aluminium or silicon depletion was found however and the resulting Al/Si ratios agree with previous work in that the particle is silicon rich at the centre. Figure 1 (c) shows two spectra from opposite edges indicating the consistency of such analyses whilst Figure 1 (d) compares a spectrum taken at the edge with one from the centre. In the latter the signal is generated throughout the depth of the particle but the enrichment in silicon is evident. Figure 1 (e) shows the results of analysis of the nearby holey carbon support film before and after examination of the crystal. The potassium appears to be "sputtered" off the particle onto the film by the electron beam, rendering measurement of the distribution of this element impossible in this case. 

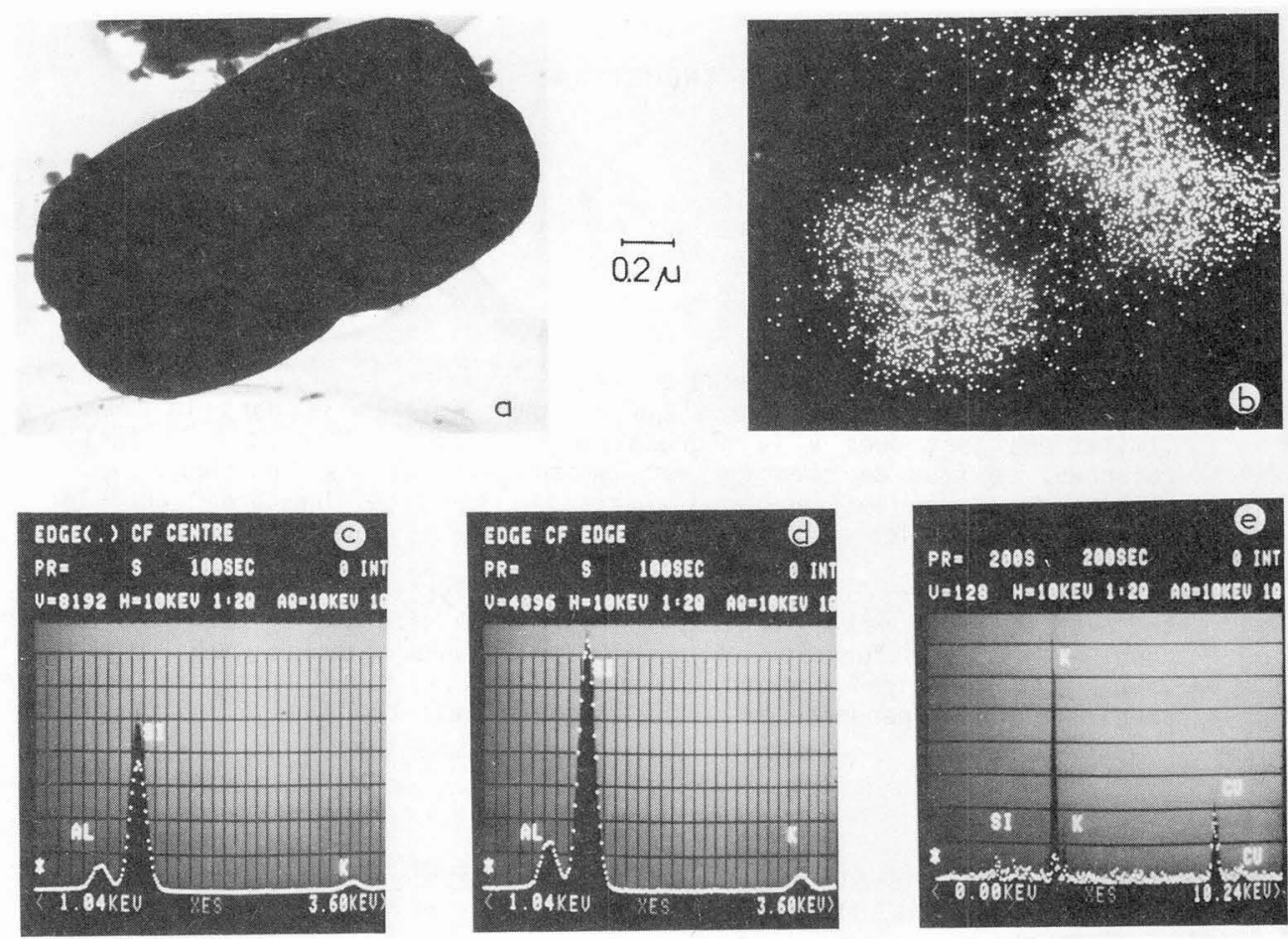

Fig. 1 - (a) Zeolite pellet after analyses of 100 seconds at the mid point of each edge and at centre; (b) potassium distribution map corresponding to (a) ; (c) a spectrum from the edge (in white) compared with that from the centre (black) ; (d) comparison of two edge analyses ; (e) spectrum from the carbonsupport before (white) and after (black) analysis of the pellet (the Cu peak is due to fluorescence of the support grid).

Damage to the heavy metal particles themselves may go so far as to destroy all trace of the particle after a few minutes $/ 5 /$, limiting useful analys is times and attainable counting statistics. In the examples below the acquisition time was Timited to 20 seconds.

The difference between "real" probe size and phase contrast image resolution has been pointed out by several authors $/ 6,7 /$. Using a large beam defining aperture in the STEM it is possible to image for example the $0.45 \mathrm{~nm}$ planes of $\mathrm{Al}_{2} \mathrm{O}_{3}$ in conditions suitable for XES analys is (Fig. 2). In th is case, however, the beam may in fact illuminate the specimen at large distances from the centre of impact.

Simple geometric optics calculations predict that the current density varies with distance from the optic axis as $r^{-4 / 3}$ at Gaussian focus, up to a value $r_{m}=C_{s}$ $\alpha^{3}$, where $C_{S}$ is the spherical aberration coefficient ( $3 \mathrm{~mm}$ in this case) and $\alpha$ the semi-angle of convergence of the beam. Increasing the beam convergence simply increases $r_{m}$, adding electrons at the edge of the probe. This will merely contribute to the background count and not increase the signal characteristic of very small particles. 


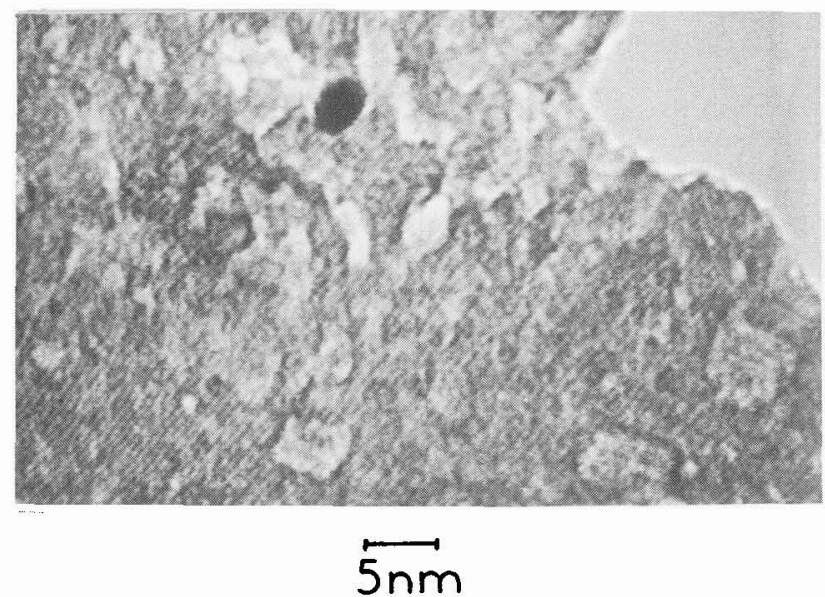

Fig. 2 - Phase contrast image of the catalyst in electron-optical conditions used for XES analysis.

Following 0ppolzer and Knauer $/ 8 /$, the count rate in a characteristic peak for a spherical particle of radius a (whose thickness varies as $2 \sqrt{a^{2}-r^{2}}$ ) is :

$$
R=\frac{I_{B}}{e} \quad \text { QW } \frac{P N}{A} \frac{\Omega}{4 \pi} \frac{\int 2 \sqrt{a^{2}-r^{2}} \cdot r^{-4 / 3} \cdot 2 \pi r d r}{\int r^{-4 / 3} \cdot 2 \pi r d r} \ldots 1
$$

where $I_{B}$ is the total beam current, $e$ the electronic charge, $Q$ the ionization cross section, $W$ the fluorescence yield, $P N / A$ the atomic density and $\Omega / 4 \pi$ the solid angle of detection of the spectrometer. The limits on the upper integral will be zero to a or $r_{m}$ whichever is the smaller, and for the lower integral zero to $r_{m}$. For beam widths very much smaller than the particle size (equivalent to the thin film case), equation 1 predicts a count rate proportional to size and beam current, whereas for $a<r_{m} R=$ const. $a^{5 / 3}$ where the constant is independant of $r_{m}$ (and therefore of $\alpha$ and $I_{B}$ ).

Figure 3 shows experimental values of $R$ for palladium particles (summing the $P d_{L}$ peaks with background subtracted) of radius $0.75 \mathrm{~nm}$ to $25 \mathrm{~nm}$. Two aperture sizes were used $\alpha=18.5 \mathrm{mrads}\left(r_{m}=19 \mathrm{~nm}, I_{B} \approx 4 n A\right)$ and $\alpha=8.5 \mathrm{mrads}\left(r_{m}=1.8 \mathrm{~nm}\right.$, $\left.I_{B} \approx I n A\right)$. Also shown are the predicted variations using $Q=2.2 \times 10^{-7} \mathrm{~nm}^{2} / 9 /$, $w=0.05 / 10 /$ and $\rho \mathrm{N} / \mathrm{A}=68 \mathrm{~nm}^{-3}$. $\Omega / 4 \pi$ was calculated from thin film measurements to be $1.3 \times 10^{-3}$.

Although statistical uncertainties are rather large, due to the short acquisition times, agreement with the theoretical variation $\left(R=4.5\right.$ a $\mathrm{a}^{5 / 3}$ irrespective of which aperture is chosen) is good whilst in the case of the smaller aperture a trend towards linear dependance $(R=10 \mathrm{a})$ is visible for particles greater than 5 $\mathrm{nm}$ in radius (i.e. for $\mathrm{a} . \gg \mathrm{rm}$ ). For the larger aperture linear dependance is expected only for particles greater than $50 \mathrm{~nm}$ in radius. 

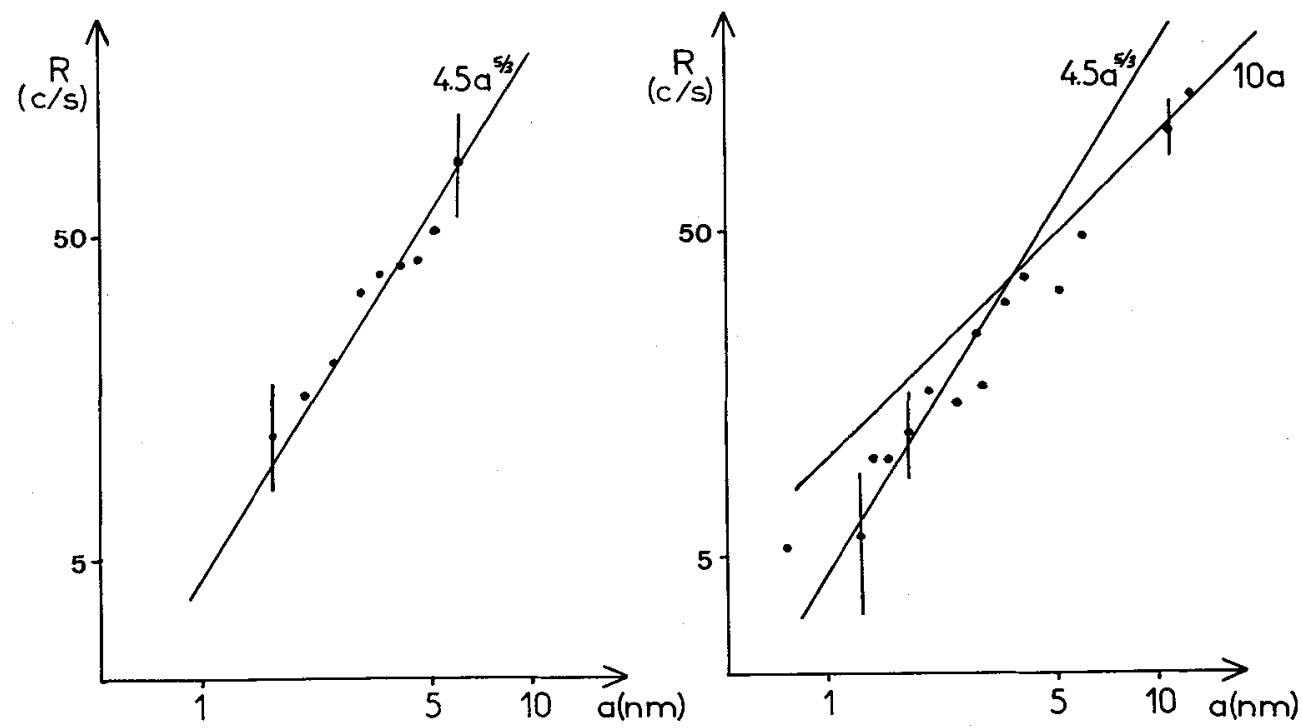

Fig. 3 - Count rate as a function of particle size for beam convergences of (a) $18.5 \mathrm{mrad}$ and (b) 8.5 mard.

The steeper dependance of count rate on size for small particles is due to electrons at the edge of the probe not interacting with the particle. Thus whilst for thin films the count rate (for $P_{d_{L}}$ ) would be $0.5 \mathrm{c} / \mathrm{s}$ per atomic layer even at monolayer thicknesses, extrapolation of the results presented here down to the case of a single atom predicts a count rate of $0.03 \mathrm{c} / \mathrm{s}$. This is well below the background level typical of the support $(\sim 0.4 \mathrm{c} / \mathrm{s})$ under the same illumination conditions, but extraction replicas on thin carbon films may present a great advantage.

\section{REFERENCES}

11/ CARPENTER R.W. and BENTLEY J., S.E.M. 1 (1979) 153.

121 hOUGHTON D.C., Inst. Phys. Conf. Ser. $N^{\circ} 61$ (1982) 245.

/3/ PENNYCOOK S.J., Contemp. Phys. 23 (1982) 371

/4/ DEXPERT H. et al. Quantitative Micro-analysis with High spatial Resolution (1981) 101

/5/ DEXPERT $H$. et al. Inst. Phys. Conf. Ser. $N^{\circ} 61$ (1982) 245

/6/ COWLEY J.M. and DISKO M.M. UItramicroscopy $\underline{5}$ (1980) 469

17/ CLIFF G. and KENWAY P.B., Microbeam Analysis (1982) 107

18/ OPPOLZER H. and KNAUER U. S.E.M. 1 (1979) 111

19/ BURHOP E.H.S. Proc. Camb. Phil. Soc. 36 (1940) 43

/10/ BAMBYNEK W. et al. Rev. Mod. Phys. 44 (1972) 716 